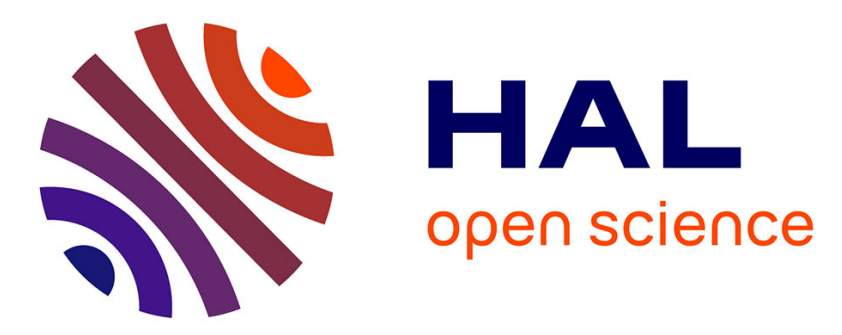

\title{
Static and dynamic bearing failure of carbon/epoxy composite joints
}

Gérald Portemont, Julien Berthe, Alain Deudon, François-Xavier Irisarri

\section{To cite this version:}

Gérald Portemont, Julien Berthe, Alain Deudon, François-Xavier Irisarri. Static and dynamic bearing failure of carbon/epoxy composite joints. Composite Structures, 2018, 204, pp.131-141. 10.1016/j.compstruct.2018.07.069 . hal-02317997

\section{HAL Id: hal-02317997 \\ https://hal.science/hal-02317997}

Submitted on 16 Oct 2019

HAL is a multi-disciplinary open access archive for the deposit and dissemination of scientific research documents, whether they are published or not. The documents may come from teaching and research institutions in France or abroad, or from public or private research centers.
L'archive ouverte pluridisciplinaire $\mathbf{H A L}$, est destinée au dépôt et à la diffusion de documents scientifiques de niveau recherche, publiés ou non, émanant des établissements d'enseignement et de recherche français ou étrangers, des laboratoires publics ou privés. 


\title{
Static and dynamic bearing failure of carbon/epoxy composite joints
}

\author{
Gérald Portemont $^{\mathrm{a}}$, Julien Berthe ${ }^{\mathrm{a}, *}$, Alain Deudon ${ }^{\mathrm{a}}$, François-Xavier \\ Irisarri $^{\mathrm{b}}$ \\ ${ }^{a}$ DMAS, ONERA, F-59014 Lille - France \\ ${ }^{b}$ DMAS, ONERA, Université Paris Saclay, F-92322 Châtillon - France
}

\begin{abstract}
Mechanical fastening is a common method used to join composite materials in aeronautical industry. Various studies have been performed dedicated to the behaviour of composite bolted joints under quasi-static loadings, but only few studies deal with the dynamic behaviour (crash or impacts). The aim of this work is to study the loading rate influence on the bearing response of a carbon/epoxy laminate loaded by a pin. For that purpose, a double shear test fixture has been specially designed to measure the global behaviour and the local response around the pin. Infrared thermography and Digital Image Correlation techniques have been used to detect, map and characterize dissipative phenomena evolution. The tests have been performed on a servohydraulic jack with a loading rate ranging from $10^{-4} \mathrm{~m} / \mathrm{s}$ to $1 \mathrm{~m} / \mathrm{s}$. An increase of the peak bearing load of more than $20 \%$ is observed with the loading rate increase. A decrease of the load plateau of more than $60 \%$ is obtained. Simultaneous measurements of thermal and kinematic fields in this work give access to the evolution of the damage-related dissipative
\end{abstract}

\footnotetext{
*Corresponding author: julien.berthe@onera.fr
} 
phenomena close to the pin. These dissipative phenomena were found to be significantly dependent on the loading rate.

Keywords: CFRP, Dynamic testing, Bearing failure, Bolted joints.

\section{Introduction}

Over the last decades, Carbon Fibre Reinforced Polymers (CFRPs) have been increasingly used in transportation industry, especially in aeronautics, in order to reduce the weight of vehicles. CFRPs represent more than $50 \%$ of the mass of the structure of the most recent Airbus and Boeing airliners. Thus, joining composite components to other composite or metallic parts is of utmost importance in the design process of such structures. Mechanical fastening is the most widespread joining method used in aeronautics for composite materials, due to the need of disassembly for maintenance tasks and the lack of reliable non-destructive control methods for bonded joints.

Mechanical fastening of composite laminates has been thoroughly examined in the literature since the 70's. Review articles on the topic can be found in [1] or [2]. First experimental studies of the composite bolted-joint behavior focused on the characterization of the main macroscopic failure modes and influencing parameters on the joint behavior (see for instance $[3,4]$ or $[5])$. In-plane failure of the joint mostly occurs by tension, shear or bearing failure, or combined failures modes. With laminates, tension and shear are catastrophic failure modes whereas bearing failure is progressive. Bearing failure develops for high width-to-hole-diameter and end-distanceto-hole-diameter ratios. Bearing strength is mostly influenced by the lay-up, the hole-diameter-to-laminate-thickness ratio, the bolt-hole clearance and the 
fastening technology. In particular, bolt lateral clamping has been shown to significantly increase the laminate quasi-static bearing strength, up to 100\%, by preventing out-of-plane damage effects under the washers $[6,7,8,9]$. In complex junctions involving more than a single row of fasteners, the joint failure is also affected by the unequal load distribution between the fasteners $[10,11,12,13,14,15]$. The load distribution between fasteners is itself influenced by the stiffness of the single-bolt elementary joint in the loading direction. Consequence of the unequal load distribution in a line of fasteners is that most elementary joints are submitted to a combination of bypass and bearing loadings that triggers a competition between tensile failure mode and bearing failure mode [16]. Fractographic analyses of the bearing failure in laminates show that bearing is due to the accumulation of local damages on the loaded side of the hole. In particular, bearing failure is driven by both fiber-kinking in the load-sustaining plies parallel to the loading direction and delamination between the plies $[7,17,18,19,20,21]$.

The aforementioned studies, deal with quasi-static testing and modeling of the composite joints. However, energy absorption capability of the bolted joint is an important factor for structural crashworthiness. The energy dissipated by one bolted joint is small, but considering the huge number of joints, the sum is no longer negligible at the scale of a complete airliner. Few studies have been published about the influence of the loading rate on the global behavior of the joint. Ger et al. [22] compared quasi-static and dynamic response (loading rates of 3 to $5 \mathrm{~m} / \mathrm{s}$ ) of CFRP and hybrid carbon and kevlar fiber reinforced plastics for various joint configurations. The authors concluded that energy absorption as well as ultimate load decreased with 
increasing loading rates. However, Li et al. [23] pointed out that the inertia effect had not been considered to calculate the dynamic failure load in [22] which could lead to unreliable conclusions. Several CFRP joint configurations with two rivets were tested at loading rates from $0.5 \mathrm{~mm} / \mathrm{min}$ to $8 \mathrm{~m} / \mathrm{s}$ in [23]. The authors concluded that increasing loading rate had no significant influence on the joint stiffness and strength, but observed an increase of the total energy absorption of the single-lap joint, mostly explained by a change of failure mode from net-tension to bearing for the highest loading rates. Coherent results were obtained by Heimbs et al. [24] who tested CFRP singlelap countersunk bolted joints up to $10 \mathrm{~m} / \mathrm{s}$. Egan et al. [25] investigated single-lap joint behavior of CFRP bolted joints at quasi-static and dynamic $(5 \mathrm{~m} / \mathrm{s}$ and $10 \mathrm{~m} / \mathrm{s})$ loading speeds. It was shown that energy absorption of the joint can be maximized by delaying the transition from progressive bearing failure to ultimate failure. Increasing the loading rate tends to favor ultimate failure by fastener pull-through over fastener failure, thus allowing more extensive bearing damage and energy absorption. Pearce et al. [26] studied the response of single fastener single-lap countersunk bolted joints with in-plane loading (bearing) or normal loading (pull-through). Loading rates vary from $0.1 \mathrm{~m} / \mathrm{s}$ to $10 \mathrm{~m} / \mathrm{s}$. Only minor loading rate dependency was observed in pull-through. For the specimen loaded in bearing, a transition was observed from fastener failure at low loading rates to pull-through at 1 $\mathrm{m} / \mathrm{s}$ and above. The energy absorption capability of bearing mode failure was specifically investigated by Heimbs and Bergmann [27]. A test set-up was devised to continuously pull a bolt through the laminated plate in a configuration somewhat similar to a double-lap pinned joint. Energy absorption 
was shown to decrease significantly with increasing loading rates in CFRP laminates.

The literature review clearly exhibits that studies related to the loading rate dependencies are classically performed on joints close to the technological solutions. In such cases, the understanding of the rate dependency is complex because of the interaction between the rivet and the composite plate which leads to a competition between bearing of the composite plate and pullthrough of the rivet. The present work is focused on the study of the loading rate dependency of the bearing response of composite plates. In section 2 , a specific experimental set-up on a servo-hydraulic jack has been devised on the principle of double shear lap test in order to perform global (load and displacement) and local measurements (digital image correlation and infrared thermography close to the pin) of the bearing response of the composite

plate. Experimental results are presented and discussed in Section 3. Tests are performed at different loading rates from $10^{-4} \mathrm{~m} / \mathrm{s}$ to $1 \mathrm{~m} / \mathrm{s}$. Global and local measurement are analysed in order to evaluate the influence of the loading rate on the bearing response.

\section{Material and methods}

\subsection{Preparation of the specimens}

The composite plates used in this study have been manufactured from Hexply M21/35\%/268/T700GC (Hexcel France) unidirectional carbon fibre prepreg plies based on a third generation epoxy resin system. The laminated plates have been cured under specific cure cycle in a hydraulic press, after hand lay-up. A generic 16-plies quasi-isotropic stacking sequence [(45/90/- 
$\left.45 / 0)_{2}\right]_{\mathrm{s}}$ is used in this study (thickness $\simeq 4.02 \mathrm{~mm}$ ). The specimens have been obtained after two machining operations (cutting and milling with appropriate tools) with the following manufacturing tolerance for the holes: $\varnothing 6.35_{-0.00}^{+0.02}$.

The characterisation of the bearing response of the CFRP laminate under quasi-static loading is normalised by the ASTM D5961 procedure [28]. The specimen geometry and dimensions used in the present work are shown in Figure 1. Because of the holder geometry of the testing machine, two notches have to be machined in the clamped area of the specimen. With this specimen design the value of the geometrical ratios influencing the behaviour of the assembly are: $\mathrm{W} / \mathrm{D}=5.6$ and $\mathrm{E} / \mathrm{D}=4.7$ with $\mathrm{D}$ the hole diameter, $\mathrm{W}$ the width of the sample and $\mathrm{E}$ the distance between the hole and the end of the specimen. Preliminary quasi-static tests have been performed to validate the bearing failure of the selected geometry.

\subsection{Experimental set-up}

The present work is focused on the analysis of the loading rate effect on the bearing failure of the laminate. According to the ASTM D5961 standard [28], the bearing response of the laminate can be studied using either a singlelap configuration or a double-lap test. However, in the case of the single-lap test, the bending effect due to the excentricity of the load path generates out-of-plane effects that can lead to fastener pull-through (see for example [25]). To prevent this unwanted failure mode, a double-lap configuration has been chosen in the following.

A specific double shear test fixture for hydraulic jack has been developed for this study. As it can be seen in the exploded diagram of the Figure 2, the 
test fixture brings several improvements with respect to the standard setup. Metallic plates (numbered 2 and 3) with high elastic limit (Ramax 1400 $\mathrm{MPa}$ ) are used to transfer the load to a metallic pin. Observation windows have been machined into the plates to enable observation of the specimen surface in front of the pin in the loading direction. The distance between the two plates is controlled by the two spacers (numbered 5 and 6) which ensure sufficient space for the specimen with a clearance of approximatively $0.2 \mathrm{~mm}$ (pre-stress is not considered in this study). The spacers also increase the overall stiffness of the set-up and prevent out-of-plane bending of the plates. The two loading plates are linked to the hydraulic jack through the part number 1 in Figure 2. To avoid relative displacement between the two loading plates during the loading, grooves have been machined into the plates. Finally, a metallic pin with a specific thermal treatment (cementation) is used to load the specimen. The test fixture has been used with a hydraulic jack to perform displacement controled tests with a loading rate varying from 5 $\mathrm{mm} \cdot \mathrm{min}^{-1}$ to $1 \mathrm{~m} \cdot \mathrm{s}^{-1}$.

\subsection{Global and local measurements}

Global and local measurements have been performed to characterise the bearing response of the composite plate under dynamic loading. The experimental set-up is shown in Figure 3. A $\pm 200 \mathrm{kN}$ piezoelectric load cell (Kistler) is used to measure the applied load on the specimen. The load cell is localised between the lower holder and the hydraulic jack support. The pin displacement is measured by means of different systems depending of the

loading rate. Between $5 \mathrm{~mm} \cdot \mathrm{min}^{-1}$ and $0.1 \mathrm{~m} \cdot \mathrm{s}^{-1}$, a Keyence laser sensor is used to monitor the displacement of the pin end. For higher loading speeds, 
a Rudoph optical extensometer is used. The measurement is based on the tracking of a black-and-white target with a resolution of $10^{-4}$ of the measuring range, which leads here to a resolution of $2 \mu \mathrm{m}$. To measure the strain in the loading direction, a strain gauge (TML YFLA-2) is glued on each specimen at a distance of $25 \mathrm{~mm}$ of the hole boundary, between the hole and the fixed jaw. The strain gauge is conditioned with a VISHAY 2310 conditioner with $75 \mathrm{kHz}$ cutting frequency.

Using the observation windows (see Figure 2), displacement and thermal field measurements have been performed on the surfaces of the specimen in the purpose of detecting in the vicinity of the hole the damage phenomena related to the progressive bearing failure of the laminate. The kinematic field are measured using 2D Digital Image Correlation (DIC) technique. The images are captured by a Photron high speed camera (Photron SA-X). In this study, two configurations of the camera have been used: 1024x1024 pixels with a frequency of $10 \mathrm{kHz}$ for loading speeds above $0.1 \mathrm{~m} . \mathrm{s}^{-1}$ and $512 \mathrm{x} 504$ pixels with a frequency of $40 \mathrm{kHz}$ for higher loading speeds. The black and white speckle pattern applied on the specimen is lightened with two high power LED projectors $(150 \mathrm{~W})$. That choice allows to reduce the exposure time in order to limit blurred area in the images. Additionally, that light technology does not influence the thermal field measurement performed on the other side of the sample [29]. To obtain the displacement field, images are divided into small areas called zone of interests (ZOI) and characterised by their grey level distribution. This characteristic distribution is used by the algorithm to find the ZOI in the deformed image and to build the displacement field. The computation of the displacement fields and strain fields are 
performed with the ARAMIS 6.1 software (GOM). For each loading speed, a ZOI of 15 x 15 pixels and a distance between the centres of two successive ZOIs of $13 \times 13$ pixels have been employed for DIC computations.

An infrared camera is used to measure the evolution of the thermal field in the hole area during dynamic loading. The camera used is a CEDIP JADE3 LWIR with 320x240 MCT detectors sensitive to the long infrared wavelength (between 8 and $12 \mu \mathrm{m}$ ) equipped with a $50 \mathrm{~mm} \mathrm{LW}$ objective. To obtain a quantitative temperature measurement the camera has to be calibrated. The calibration is performed by putting a blackbody in front of the camera. Images are taken for different surface temperature of the blackbody and a global response law of the matrix is built to link the digital level measured to the temperature. In this study, the objective is to measure small temperature gradients at the surface of the specimen over few pixels of the IR camera. Indeed, the first bearing damages are localised in a small area near the loaded boundary of the hole. Some authors have shown that in such a case an alternative calibration method is required to increase the accuracy of the temperature measurement $[30,31]$. In this alternative method the calibration law of the matrix is replaced by a calibration law for each pixel. In this study, the pixel-by-pixel calibration procedure has been performed in the environment of the subsequent experimental investigation. The interval of temperature used for the calibration phase ranges from $18^{\circ} \mathrm{C}$ to $40^{\circ} \mathrm{C}$ by steps of $0.5^{\circ} \mathrm{C}$. For each temperature value 100 images of the SR800 blackbody (CI Systems) have been taken and the mean of these images has been used to generate the calibration law (6 order polynomial law) of each pixel using MATLAB. In this study, after calibration, the difference between the mean 
temperature measure by the camera and the real blackbody temperature was lower than $0.015^{\circ} \mathrm{C}$ between $18^{\circ} \mathrm{C}$ and $30^{\circ} \mathrm{C}$ and lower than $0.02^{\circ} \mathrm{C}$ between $30^{\circ} \mathrm{C}$ and $40^{\circ} \mathrm{C}$.

To synchronise all measurement systems and to record data a 1-MHz data acquisition system has been used (NICOLET).

\section{Results}

To study in detail the loading rate dependency, tests have been performed for five different speeds: $8.3 \cdot 10^{-5} \mathrm{~m} . \mathrm{s}^{-1}, 1 \cdot 10^{-3} \mathrm{~m} . \mathrm{s}^{-1}, 8.3 \cdot 10^{-3} \mathrm{~m} . \mathrm{s}^{-1}, 0.1$ $\mathrm{m} . \mathrm{s}^{-1}$ and $1 \mathrm{~m} \cdot \mathrm{s}^{-1}$. As shown in Table 1, for each speed at least three tests have been performed to check repeatability. In the following, the experimental results are analysed in three phases. First, the consistency of the different load and displacements measurements systems employed is checked using a quasi-static test. Second, the influence of the loading rates on the global bearing response of the specimens is analysed. Finally, a local analysis is performed thanks to digital image correlation and infrared thermography. The objective of this analysis is to gain insight into the influence of the loading rate on the material behaviour near the hole.

\subsection{Consistency of the load and displacement measurement systems}

As it is shown in Figure 4, for each tests the applied load (blue curve), the pin displacement (red curve) and the strain measured by the strain gauge (green curve) are recorded. Concerning the pin displacement, two different measuring system are used depending of the loading rate. A comparison of the displacement obtained by the two means have been performed on quasistatic test $\left(8.3 \cdot 10^{-5} \mathrm{~m} . \mathrm{s}^{-1}\right)$ and a difference of $10 \mu \mathrm{m}$ is obtained for the value 
of the displacement at the bearing peak, which corresponds to a variation of $2.5 \%$ of the bearing peak value.

The Figure 4 also shows that the strain curve and the load curve have the same shape. Apparently, the strain measurement is not disturb by the perforation as it is performed at a sufficient distance of the hole. Therefore, the applied load can also be calculated with the gauge measurement knowing the elastic properties of the laminate, which is interesting for high loading rate when the load measurement can be disturbed by the load cell resonance frequency.

\subsection{Global bearing response of the laminates}

Experimental results for the three tests performed at $1 \mathrm{~m} \cdot \mathrm{s}^{-1}$ plotted in Figure 5 illustrate the repeatability of the tests even for dynamic loading rates. The applied load is plotted on the $\mathrm{y}$-axis and the pin displacement is plotted on the x-axis. Based on this figure, the bearing response of the laminate plate can be divided in several phases:

1. at the begin of the test, some displacements can be observed without applied load on the specimen, this phase corresponds to the decrease of the existing clearance in the experimental set-up,

2. next the assembly exhibits a linear behaviour, characterised by a rigidity denoted $K_{e}$ in the sequel, followed by the begin of the non linear behaviour of the assembly,

3. this non linear behaviour leads to the bearing peak for a an applied load denoted $F_{\text {peak }}$ (between $15 \mathrm{kN}$ and $16 \mathrm{kN}$ in Figure 5) and a pin displacement denoted $\delta_{\text {peak }}$ (between $0.4 \mathrm{~mm}$ and $0.5 \mathrm{~mm}$ in Figure 5) followed by a brutal decrease of the strength of the assembly, 
4. finally a load plateau appears after a stabilisation phase (for a displacement larger than $1.5 \mathrm{~mm}$ in Figure 5), the load plateau amplitude is denoted $F_{\text {plat }}$ in the following and is evaluated as the mean value between $5 \mathrm{~mm}$ and $10 \mathrm{~mm}$.

The evolution of the bearing response with respect to the loading rate is plotted in Figure 6. For sake of clarity, the displacement is plotted until 9 $\mathrm{mm}$ as no major evolution is observed after such a displacement, even if all the signals have been recorded until the end of the test. The Figure 6 clearly exhibits a rate dependency of the bearing response for this laminate. The rate dependency is also observable in Table 1 and Figure ??, in which the results obtained on the different tests for the previously defined parameters $\left(K_{e}, \delta_{\text {peak }}\right.$ and $\left.F_{\text {plat }}\right)$ are summarised. Firstly, an increase of the peak bearing load is observed with the loading rate increase, from an average value of 12.7 $\mathrm{kN}$ for $8.3 \cdot 10^{-5} \mathrm{~m} . \mathrm{s}^{-1}$ tests to $15.5 \mathrm{kN}$ for $1 \mathrm{~m} . \mathrm{s}^{-1}$ tests. The pin displacement at the bearing peak also increases from $0.4 \mathrm{~mm}$ to $0.5 \mathrm{~mm}$. Secondly, the magnitude of the load plateau is decreasing with the loading rate increase, from $10.3 \mathrm{kN}$ for $8.3 \cdot 10^{-5} \mathrm{~m} . \mathrm{s}^{-1}$ tests to $6.3 \mathrm{kN}$ for $1 \mathrm{~m} . \mathrm{s}^{-1}$ tests (see Table 1 ). Contrary to the aforementioned parameters, the assembly linear behaviour does not appear to be loading rate dependent, this is an expected results for carbon/epoxy quasi-isotropic plates as the stiffness of the $0^{\circ}$ plies is not rate dependent. On the other hand, the strain rate dependency of the compressive strength of the $0^{\circ}$ plies could be responsible of the increase of the bearing peak, as the bearing peak is due to the kinking of the fibres in the $0^{\circ}$ plies $[32]$. 


\subsection{Local bearing response of the laminates}

\subsubsection{Infrared Thermography analysis for a quasi-static test}

The Infrared Thermography (IT) analysis is performed until the bearing peak at which the $45^{\circ}$ surface ply disturbs the measurement by being unsticked of the rest of the laminate. As the computer based triggering of the JADE III infrared camera is not as efficient as the direct triggering of visible cameras, the infrared films have been readjusted using the bearing peak as stopping point. Indeed, this brutal phenomenon with intense dissipative activity is easily detectable on infrared images. Given the properties of the infrared camera, measurements have only been performed for load-

ing speeds lower to $0.1 \mathrm{~m} . \mathrm{s}^{-1}$. For the tests performed, the infrared camera configurations are summarised in Table 2.

In the following, the analysis of the thermography images is based on the three zones in the pin area described in Figure 8. The difference between the two radius of each zone is equal to the half of the radius of the pin. Here, damage-related small variations of the temperature are expected (see [33]), consequently the change of temperature $\Delta T$ is preferred to the absolute temperature value to perform the analysis. The temperature change is mainly due to the applied loading through thermoelasticity and the apparition of dissipative phenomenon through damage. In order to detect damage appearance, the change of temperature $\Delta T$ is computed using a sliding window with a length corresponding to $1 \%$ of the total number of images for the tests:

$$
\Delta T(i)=T(i)-T\left(i-\frac{1}{100} N_{t o t}\right)
$$

here $N_{\text {tot }}$ is the number of images for the studied test. As the load increase is almost linear until the bearing peak (see Figure 4), the change of temperature 
due to thermoelasticity is almost constant for all the $\Delta T$ computed. Given the length of the sliding window, its magnitude is limited.

In Figure 9, the evolution of the mean temperature change with respect to the applied load is plotted in zone 1 for the A-01 test. As expected, thanks to the sliding window processing, the temperature change $\Delta T$ does not evolve until the first damage event appearance. For an applied load of about 6.7 $\mathrm{kN}$, the first significant $\Delta T$ variation highlights the appearance of a matrix crack in the $45^{\circ}$ surface ply long before the bearing peak. Shortly after the appearance of the crack matrix, another $\Delta T$ variation can be observed, with higher magnitude and duration. The two cartographies taken for an applied load of about $8.7 \mathrm{kN}$ and $9.6 \mathrm{kN}$ and illustrating this temperature change peak, illustrate a more diffuse dissipative phenomenon. This explains the higher magnitude observed since the mean value is more impacted by a diffuse phenomenon. It is assumed here that this dissipative phenomenon can be related to delaminations occurring near the loaded boundary of the hole. As a matter of facts, such local damages have already been reported in the litterature for quasi-static tests (see for instance Camanho et al. [32], using Xradiography and sectioning).

In Figure 10, a comparison of the temperature change mean values in the different zones previously defined is performed on the same low speed tests. These curves highlights the propagation of the dissipative phenomenon to distant regions well before the bearing peak. The magnitude of the peak decreases as the zone is farther from the pin. This can be explain in different ways. Firstly, as the mean value is considered, the magnitude of the peak is influenced by the distribution of the dissipative phenomenon on the con- 
sidered area. Secondly, the intensity of the dissipative phenomenon could be lower in an area far from the pin.

\subsubsection{Digital Image Correlation analysis for a quasi-static test}

In this study, Digital image correlation is used to analyse strain fields $\left(\varepsilon_{x x}, \varepsilon_{y y}\right.$ and $\left.\varepsilon_{x y}\right)$ ahead of the pin. In Figure 11, the longitudinal $\varepsilon_{x x}$ (with the x-axis corresponding to the loading direction), transversal $\varepsilon_{y y}$ and shear $\varepsilon_{x y}$ strain fields are plotted just before the bearing peak. Some discontinuities can be observed on these strain fields particularly in the area near to the pin for $\varepsilon_{y y}$ and $\varepsilon_{x y}$. The shape of these discontinuities is similar to the matrix cracking in the $45^{\circ}$ ply, previously observed with IT measurement. An efficient way to detect crack with DIC measurement is to analysed the residual field [34]. As Aramis software is used in this study, the authors do not have access to the residual field. In this case, a visual analysis of

the strain field can be performed in order to evaluate the appearance time of the crack. However, this analysis is user dependent and will lead to an important uncertainty. Consequently, a similar approach to the one applied on the thermal field in Section 3.3.1 is proposed in the following to analyse the strain fields.

The strain mean values are computed in the same three areas previously defined in Figure 8 for IT analysis. The variation of the mean values of the longitudinal strain $\varepsilon_{x x}^{-}$in the three areas is plotted in Figure 12 with respect to the applied load. The figure clearly exhibits that the deformation is mostly localised in the first area. It can also be noticed that the evolution of $\varepsilon_{x x}^{-}$in the first zone is initially linear and becomes more and more non-linear with the load increase. The transition between the linear and non-linear evolution 
occurs to appear between $6 \mathrm{kN}$ and $8 \mathrm{kN}$. This order of magnitude can be linked to the increase of temperature previously observed in IT analysis.

Finally, the field of strain variation $\Delta \varepsilon$ during the test with the same sliding window as for the IT analysis can be studied. In Figure 13, the variation of the shear strain field $\Delta \varepsilon_{x y}$ is plotted before and after a crack appearance in the surface ply. These figures clearly reveal the crack and only the crack. For this loading speed, the matrix crack is observed for a load applied on the specimen of $77.1 \%$ of the bearing peak load (see Table 3). This value is higher than the one obtained for IT analysis $(54.5 \%$ of the bearing peak load, see Table 2). This can be explained first by the fact that the measurements are performed on opposite faces which can lead to a delay. The delay can also by explained by the fact that due to the use of ZOI to compute displacement and strain field, DIC cannot capture the crack appearance close to the pin. The crack is captured by DIC when its propagation is sufficient, contrary to the infrared thermography which can measure dissipative phenomenon close to the pin.

\subsubsection{Scattering of the test results}

Even if the scattering is relatively low for the global measurement results, higher scattering has been obtained on local measurement results. For example, the comparison of the results obtained with IR analysis for two tests performed at $8.3 \cdot 10^{-3}$ m.s ${ }^{-1}$ is plotted in Figure 14 for zone 1. For the second test, the matrix crack appears for lower load level. Nevertheless, the observed scenario remains the same: the crack appearance in the surface $45^{\circ}$ ply is followed by a more diffuse dissipative phenomenon ahead of the pin. Such scattering can also be observed for DIC analysis at the same loading rate as 
shown in Figure 15a. This scattering could be due to differences in the way to apply the load to the composite plate. For example, a small coaxiality default can lead to a difference in the applied load to the surface ply. Finally, at higher loading rate, a smaller scattering is observed as it can be noticed in Figure 15b. The scattering decrease with the increase of the loading rate has also been observed for the results obtained with IT analysis.

\subsubsection{Loading rate dependency}

Concerning the influence of the loading rate, the evolution of the temperature change mean value is plotted in Figure 16 for a loading speed of $1 \cdot 10^{-3}$ $\mathrm{m} . \mathrm{s}^{-1}$ and in Figure 17 for the tests performed at $8.3 \cdot 10^{-3} \mathrm{~m} \cdot \mathrm{s}^{-1}$. Given the properties of the infrared camera, measurements have only been performed for loading speeds lower to $0.1 \mathrm{~m} \cdot \mathrm{s}^{-1}$. As previously, the appearance of a matrix crack in the $45^{\circ}$ surface ply is observed. The scenario is similar to one previously described, the cracking is followed by a diffuse dissipative activity ahead of the pin. As observed in Figure 17, for the higher loading rate multiple cracks are observed contrary to lower loading rate tests. The first conclusion regarding the influence of the loading speed is that the load level leading to matrix cracking in the surface ply is rate dependant (see Table 2).

Rate dependency is also observed in DIC results. In Figure 18, the evolution of the mean longitudinal strain field in zone 1 is plotted for different loading rate. The sliding window processing can only be efficiently applied on the 4 lower speeds (not enough points to obtain relevant results for the $1 \mathrm{~m} / \mathrm{s}$ test). A delay in the appearance of the transition between linear and non linear evolution is observed with the increase of the loading rate. This results is in good agreement with the delay in the appearance of the matrix 
crack in the surface ply.

Finally, the analysis can also be performed regarding different areas ahead of the pin. For the $1 \cdot 10^{-3}$ m.s ${ }^{-1}$, this analysis is performed in Figure 16. It appears that the area in which dissipative phenomenon happens is smaller than for the low speed tests. A limited dissipative activity is noticed in the second area of analysis and almost no activity in the third area. Again, these

results are confirmed by tests performed at $8.3 \cdot 10^{-3} \mathrm{~m} \cdot \mathrm{s}^{-1}$. The evolutions of the mean value of $\Delta T$ in the second and third area are respectively limited and unnoticeable. This leads to the second conclusion of this IT analysis which is that the area of dissipative activity ahead of the pin is less extended with the increase of the speed. The higher the speed, the shorter the damage area is.

\section{Conclusions}

In this paper, the loading rate dependency of the bearing response of quasi-isotropic T700GC/M21 composite laminates has been studied. For that purpose a specific double-lap experimental set-up has been designed in order to perform global and local measurements of the bearing response of the composite plate. Tests have been performed at different loading rates from $5 \mathrm{~mm} / \mathrm{min}$ up to $1 \mathrm{~m} / \mathrm{s}$ with a servo-hydraulic jack.

Regarding the global response of the laminate, the experimental results show a significant influence of the loading rate. The peak bearing load increases by about $20 \%$ with respect to the quasi-static response when the loading rate increases from $8 \cdot 3 \cdot 10^{-5} \mathrm{~m} / \mathrm{s}$ to $1 \mathrm{~m} / \mathrm{s}$. On the same range of loading rate, the load plateau falls by about $40 \%$. Conversely, the stiffness 
of the joints in its phase of linear behaviour does not seem to be influenced by the loading rate.

Concerning local measurements, DIC and IT exhibit local non linear behaviour, with for example matrix cracking in the surface ply, which is not observed on global measurement. The local non linearity observed with these two techniques is loading rate dependent. Firstly, a delay in the appearance of the non linear phenomenon is observed with the loading rate increase. Secondly, the area of dissipative activity ahead of the pin is less extended with the increase of the loading rate. The higher the loading rate, the shorter the damage area is.

\section{Acknowledgements}

The authors gratefully acknowledge funding of VulcompII project by the French National Research Agency (ANR) and of the PRF TSD project by ONERA.

\section{References}

[1] Camanho P, Matthews F. Stress analysis and strength prediction of mechanically fastened joints in FRP: a review. Composites Part A: Applied Science and Manufacturing 1997;28(6):529-47. doi:10.1016/S1359835X(97)00004-3.

[2] Thoppul SD, Finegan J, Gibson RF. Mechanics of mechanically fastened joints in polymermatrix composite structures A review. Composites Science and Technology 2009;69(3-4):301-29. doi: 10.1016/j.compscitech.2008.09.037. 
[3] Collings TA. On the bearing strengths of CFRP laminates. Composites 1982;13(3):241-52.

[4] Collings TA, Beauchamp MJ. Bearing deflection behaviour of a loaded hole in CFRP. Composites 1984;15(1):33-8.

[5] Hart-Smith LJ. Bolted Joints In Graphite-Epoxy Composites. Tech. Rep.; MCDONNELL DOUGLAS CORP LONG BEACH CA DOUGLAS AIRCRAFT DIV.; 1976.

[6] Park HJ. Bearing failure analysis of mechanically fastened joints in composite laminates. Composite Structures 2001;53(2):199-211. doi: 10.1016/S0263-8223(01)00004-6.

[7] Kelly G, Hallstrm S. Bearing strength of carbon fibre/epoxy laminates: effects of bolt-hole clearance. Composites Part B: Engineering 2004;35(4):331-43. doi:10.1016/j.compositesb.2003.11.001.

[8] Khashaba U, Sallam H, Al-Shorbagy A, Seif M. Effect of washer size and tightening torque on the performance of bolted joints in composite structures. Composite Structures 2006;73(3):310-7. doi: 10.1016/j.compstruct.2005.02.004.

[9] Irisarri FX, Vandellos T, Paulmier P, Laurin F. Experiments and modeling of clamping effects on the bearing strength of mechanically fastened joint in CFRP laminates. Seville, Spain; 2014,.

[10] Tate MB. Preliminary investigation of the loads carried by individual bolts in bolted joints. Tech. Rep. NACA-TN-1051; 1946. 
[11] Ross RD. An Electrical Computer for the Solution of Shear-Lag and Bolted-Joint Problems. Tech. Rep. NACA-TN-1281; NATIONAL ADVISORY COMMITTEE FOR AERONAUTICS LANGLEY FIELD VA LANGLEY AERONAUTICAL LABORATORY; 1947.

[12] McCarthy M, McCarthy C, Padhi G. A simple method for determining the effects of bolthole clearance on load distribution in single-column multi-bolt composite joints. Composite Structures 2006;73(1):78-87. doi:10.1016/j.compstruct.2005.01.028.

[13] Ekh J, Schn J. Finite element modeling and optimization of load transfer in multi-fastener joints using structural elements. Composite Structures 2008;82(2):245-56. doi:10.1016/j.compstruct.2007.01.005.

[14] Gray P, McCarthy C. A global bolted joint model for finite element analysis of load distributions in multi-bolt composite joints. Composites Part B: Engineering 2010;41(4):317-25. doi: 10.1016/j.compositesb.2010.03.001.

[15] Lecomte J, Bois C, Wargnier H, Wahl JC. An analytical model for the prediction of load distribution in multi-bolt composite joints including hole-location errors. Composite Structures 2014;117:354-61. doi: 10.1016/j.compstruct.2014.06.040.

[16] Crews Jr JH, Naik RA. Bearing-bypass loading on bolted composite joints. Tech. Rep. NASA-TM-89153; 1987.

[17] Wu P, Sun C. Modeling bearing failure initiation in pin-contact of 
composite laminates. Mechanics of Materials 1998;29(3-4):325-35. doi: 10.1016/S0167-6636(98)00019-2.

[18] Ireman T, Ranvik T, Eriksson I. On damage development in mechanically fastened composite laminates. Composite Structures 2000;49(2):151-71. doi:10.1016/S0263-8223(99)00130-0.

[19] Xiao Y, Ishikawa T. Bearing strength and failure behavior of bolted composite joints (part I: Experimental investigation). Composites Science and Technology 2005;65(7-8):1022-31. doi: 10.1016/j.compscitech.2005.02.011.

[20] Irisarri FX, Laurin F, Carrere N, Maire JF. Progressive damage and failure of mechanically fastened joints in CFRP laminates Part I: Refined Finite Element modelling of single-fastener joints. Composite Structures 2012;94(8):2269-77. doi:10.1016/j.compstruct.2011.07.023.

[21] Sola C, Castani B, Michel L, Lachaud F, Delabie A, Mermoz E. On the role of kinking in the bearing failure of composite laminates. Composite Structures 2016;141:184-93. doi:10.1016/j.compstruct.2016.01.058.

[22] Ger G, Kawata K, Itabashi M. Dynamic tensile strength of composite laminate joints fastened mechanically. Theoretical and Applied Fracture Mechanics 1996;24(2):147-55. doi:10.1016/0167-8442(95)00038-0.

[23] Li QM, Mines RAW, Birch RS. Static and dynamic behaviour of composite riveted joints in tension. International journal of mechanical sciences 2001;43(7):1591-610. 
[24] Heimbs S, Schmeer S, Blaurock J, Steeger S. Static and dynamic failure behaviour of bolted joints in carbon fibre composites. Composites Part A: Applied Science and Manufacturing 2013;47:91-101. doi: 10.1016/j.compositesa.2012.12.003.

[25] Egan B, McCarthy C, McCarthy M, Gray P, OHiggins R. Static and high-rate loading of single and multi-bolt carbonepoxy aircraft fuselage joints. Composites Part A: Applied Science and Manufacturing 2013;53:97-108. doi:10.1016/j.compositesa.2013.05.006.

[26] Pearce GM, Johnson AF, Thomson RS, Kelly DW. Experimental Investigation of Dynamically Loaded Bolted Joints in Carbon Fibre Composite Structures. Applied Composite Materials 2010;17(3):271-91. doi: 10.1007/s10443-009-9120-8.

[27] Heimbs S, Bergmann T. Bearing Mode Absorber On the Energy Absorption Capability of Pulling a Bolt through a Composite or Sandwich Plate. Procedia Engineering 2014;88:149-56. doi: 10.1016/j.proeng.2014.11.138.

[28] ASTM International . ASTM D5961 : 2001 : Standard test method for bearing response of polymer matrix composite laminates. ASTM International; 2001.

[29] Crump D, Dulieu-Barton J, Longana M. Measuring visco-elastic behaviour of composites at high strain rates using optical techniques. Applied Mechanics and Materials 2011;70:75-80. 
[30] Poncelet M. Multiaxialit, htrognits intrinsques et structurales des essais d'auto-chauffement et de fatigue grand nombre de cycles. Ph.D. thesis; ENS Cachan; 2007.

[31] Bodelot L, Sabatier L, Charkaluk E, Dufrénoy P. Experimental setup for fully coupled kinematic and thermal measurements at the microstructure scale of an aisi 3161 steel. Materials Science and Engineering: A 2009;501(1):52-60.

[32] Camanho P, Bowron S, Matthews F. Failure mechanisms in bolted cfrp. Journal of Reinforced Plastics and Composites 1998;17(3):205-33.

[33] Fruehmann R, Dulieu-Barton J, Quinn S. Thermoelastic stress and damage analysis using transient loading. Experimental mechanics 2010;50(7):1075-86.

[34] Roux S, Réthoré J, Hild F. Digital image correlation and fracture: an advanced technique for estimating stress intensity factors of $2 \mathrm{~d}$ and $3 \mathrm{~d}$ cracks. Journal of Physics D: Applied Physics 2009;42(21). 


\section{List of Figures}

1 Specimen dimensions . . . . . . . . . . . . . . . . . . . . . . 29

2 Exploded diagram of the double shear test fixture . . . . . . . 29

3 Global views of the experimental set-up with the different measurement systems . . . . . . . . . . . . . . . . 30

4 Evolution of the load, displacement and strain measured values during a $8 \cdot 3 \cdot 10^{-5} \mathrm{~m} \cdot \mathrm{s}^{-1}$ test $\ldots \ldots \ldots$. . . . . . 30

5 Evolution of the different measured values for the three tests performed at $1 \mathrm{~m} \cdot \mathrm{s}^{-1} \ldots \ldots \ldots \ldots \ldots$. . . . . . . . 31

6 Evolution of the bearing response with respect to the loading rates . . . . . . . . . . . . . . . . . . 31

7 Test results evolution of the global bearing parameters with respect to the loading rate . . . . . . . . . . . . . . . 32

8 Description of the three processing zones for the IT and DIC analyse . . . . . . . . . . . . . . . . 33

9 Evolution of the mean value of temperature change computed with the sliding windows for a test speed of $8.3 \cdot 10^{-5} \mathrm{~m} . \mathrm{s}^{-1}$ in Zone $1 \ldots \ldots$. . . . . . . . . . . . . . . . 33

10 Evolution of the mean value of the temperature change computed with the sliding windows for a test speed of $8.3 \cdot 10^{-5}$ $\mathrm{m} \cdot \mathrm{s}^{-1}$ in zones 1 to $3 \ldots \ldots \ldots \ldots \ldots$

11 Strain fields observed just before the bearing peak $F=12950 \mathrm{~N}$ for a test speed of $8 \cdot 3 \cdot 10^{-5} \mathrm{~m} \cdot \mathrm{s}^{-1} \ldots \ldots \ldots$. . . . . . 34

12 Evolution of the mean of the strain $\varepsilon_{x x}$ for a test speed of $8.3 \cdot 10^{-5} \mathrm{~m} \cdot \mathrm{s}^{-1}$ in different zone close to the pin . . . . . . . 35 
13 Map of the shear strain field variation $\Delta \varepsilon_{x y}$ plotted just before the matrix cracking in the surface ply on the left hand side $F=11750 N$ and just after on the right hand side $F=11778 N$ for a test speed of $8.3 \cdot 10^{-5} \mathrm{~m} \cdot \mathrm{s}^{-1}$. . . . . . . . . . . . 36

14 Comparison of the evolution of the temperature change mean value for two tests performed at $8.3 \cdot 10^{-5} \mathrm{~m} . \mathrm{s}^{-1}$ in the first zone close to the pin . . . . . . . . . . . . . 37

15 Evolution of the mean of the strain $\varepsilon_{x x}$ in zone1 for all tests performed for the loading rate of $8.3 \cdot 10^{-5} \mathrm{~m} . \mathrm{s}^{-1}$ (left hand side) and for the loading rate of $0.1 \mathrm{~m} . \mathrm{s}^{-1}$ (right hand side) . 38

16 Evolution of $\Delta T$ mean value for a test speed of $1 \cdot 10^{-3} \mathrm{~m} . \mathrm{s}^{-1}$ in different zone close to the pin . . . . . . . . . . . 38

17 Evolution of $\Delta T$ mean value in the zone 1 (see Figure 8) for the three tests performed at $8.3 \cdot 10^{-3} \mathrm{~m} \cdot \mathrm{s}^{-1}$. . . . . . . . 39

18 Evolution of the mean of the strain $\varepsilon_{x x}$ for all speed in zone1 . 40 


\begin{tabular}{|c|c|c|c|c|}
\hline \multicolumn{5}{|c|}{ a- $8.3 \cdot 10^{-5} \mathrm{~m} . \mathrm{s}^{-1}$} \\
\hline $\begin{array}{c}\text { Test } \\
\text { Number }\end{array}$ & $\begin{array}{c}K_{e} \\
\left(\mathrm{kN} \cdot \mathrm{mm}^{-1}\right)\end{array}$ & $\begin{array}{c}F_{\text {peak }} \\
(\mathrm{kN})\end{array}$ & $\begin{array}{l}\delta_{\text {peak }} \\
(\mathrm{mm})\end{array}$ & $\begin{array}{l}F_{\text {plat }} \\
(\mathrm{kN})\end{array}$ \\
\hline $\mathrm{A}-01$ & 39.6 & 12.4 & 0.41 & 10.3 \\
\hline $\mathrm{A}-02$ & 37.2 & 12.8 & 0.46 & 9.8 \\
\hline A-03 & 38.0 & 12.9 & 0.44 & 10.2 \\
\hline mean & 38.3 & 12.7 & 0.44 & 10.1 \\
\hline standard deviation & 1.2 & 0.3 & 0.03 & 0.3 \\
\hline \multicolumn{5}{|c|}{ b- $1 \cdot 10^{-3} \mathrm{~m} \cdot \mathrm{s}^{-1}$} \\
\hline $\mathrm{A}-04$ & 40.9 & 13.4 & 0.4 & 9.9 \\
\hline $\mathrm{A}-05$ & 39.9 & 13.7 & 0.4 & 9.9 \\
\hline A-06 & 42.2 & 13.8 & 0.4 & 10.2 \\
\hline mean & 41.0 & 13.6 & 0.4 & 10.0 \\
\hline standard deviation & 1.2 & 0.2 & 0.0 & 0.2 \\
\hline \multicolumn{5}{|c|}{ c- $8.3 \cdot 10^{-3} \mathrm{~m} . \mathrm{s}^{-1}$} \\
\hline $\mathrm{A}-07$ & 39.1 & 14.6 & 0.42 & 8 \\
\hline $\mathrm{A}-08$ & 40.9 & 14.4 & 0.41 & 8.2 \\
\hline $\mathrm{A}-09$ & 37.8 & 14.3 & 0.40 & 7.7 \\
\hline mean & 39.3 & 14.4 & 0.41 & 8.0 \\
\hline standard deviation & 1.6 & 0.2 & 0.01 & 0.3 \\
\hline \multicolumn{5}{|c|}{$\mathrm{d}-0.1 \mathrm{~m} \cdot \mathrm{s}^{-1}$} \\
\hline $\mathrm{A}-10$ & 39.9 & 15.7 & 0.61 & 6.6 \\
\hline $\mathrm{A}-11$ & 43.2 & 15.6 & 0.63 & 7.4 \\
\hline $\mathrm{A}-12$ & 44.0 & 15.0 & 0.54 & 7.3 \\
\hline mean & 42.4 & 15.4 & 0.59 & 7.1 \\
\hline standard deviation & 2.2 & 0.4 & 0.05 & 0.5 \\
\hline \multicolumn{5}{|c|}{ e- $1 \mathrm{~m} \cdot \mathrm{s}^{-1}$} \\
\hline $\mathrm{A}-13$ & 38.4 & 15.4 & 0.51 & 6.3 \\
\hline $\mathrm{A}-14$ & 39.2 & 15.9 & 0.47 & 6.2 \\
\hline $\mathrm{A}-15$ & 36.6 & 15.2 & 0.47 & 6.3 \\
\hline mean & 38.1 & 15.5 & 0.48 & 6.3 \\
\hline standard deviation & 1.3 & 0.4 & 0.03 & 0.1 \\
\hline
\end{tabular}

Table 1: Test results evolution of the global bearing parameters with respect to the loading rate 


\begin{tabular}{|c|c|c|c|c|}
\hline $\begin{array}{c}\text { Test speed } \\
\left(\mathrm{m} \cdot \mathrm{s}^{-1}\right)\end{array}$ & $\begin{array}{c}\text { Frequency } \\
(\mathrm{Hz})\end{array}$ & $\begin{array}{c}\text { Image size } \\
(\text { pixels x pixels })\end{array}$ & $\begin{array}{c}\text { Integration time } \\
(\mu \mathrm{s})\end{array}$ & $\begin{array}{c}\text { Matrix cracking appearance } \\
(\% \text { of the bearing peak })\end{array}$ \\
\hline $8.3 \cdot 10^{-5}$ & 1250 & $80 \times 65$ & 360 & 54.5 \\
$1 \cdot 10^{-3}$ & 1000 & $80 \times 65$ & 360 & 76.4 \\
$8.3 \cdot 10^{-3}$ & 1250 & $80 \times 65$ & 360 & 80.9 \\
0.1 & 1500 & $80 \times 34$ & 360 & - \\
\hline
\end{tabular}

Table 2: Configuration of the infrared camera for the various tests and results concerning the matrix cracking appearance obtained with IR analysis

\begin{tabular}{|c|c|c|c|}
\hline $\begin{array}{c}\text { Test speed } \\
\left(\mathrm{m}_{\mathrm{s}}{ }^{-1}\right)\end{array}$ & $\begin{array}{c}\text { Frequency } \\
(\mathrm{Hz})\end{array}$ & $\begin{array}{c}\text { Image size } \\
(\text { pixels } \times \text { pixels })\end{array}$ & $\begin{array}{c}\text { Matrix cracking detection } \\
\text { (\% of the bearing peak) }\end{array}$ \\
\hline $8.3 \cdot 10^{-5}$ & 50 & $1024 \times 1024$ & 77.1 \\
$1 \cdot 10^{-3}$ & 1000 & $1024 \times 1024$ & 77.5 \\
$8.3 \cdot 10^{-3}$ & 5000 & $1024 \times 1024$ & 77.0 \\
0.1 & 27000 & $1024 \times 1024$ & 81.7 \\
1 & 40000 & $1024 \times 1024$ & 89.8 \\
\hline
\end{tabular}

Table 3: Configuration of the high speed camera for the various tests and results concerning the matrix cracking appearance obtained with DIC 


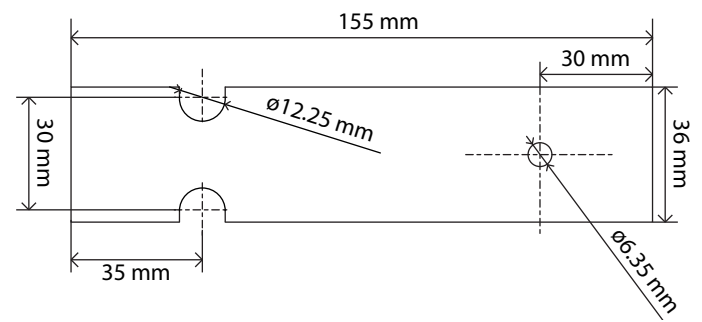

Figure 1: Specimen dimensions

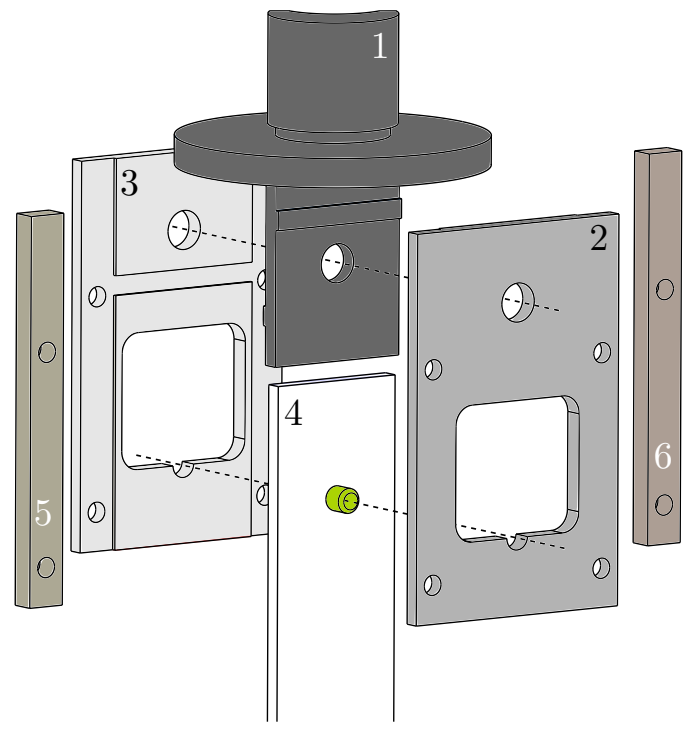

Figure 2: Exploded diagram of the double shear test fixture 


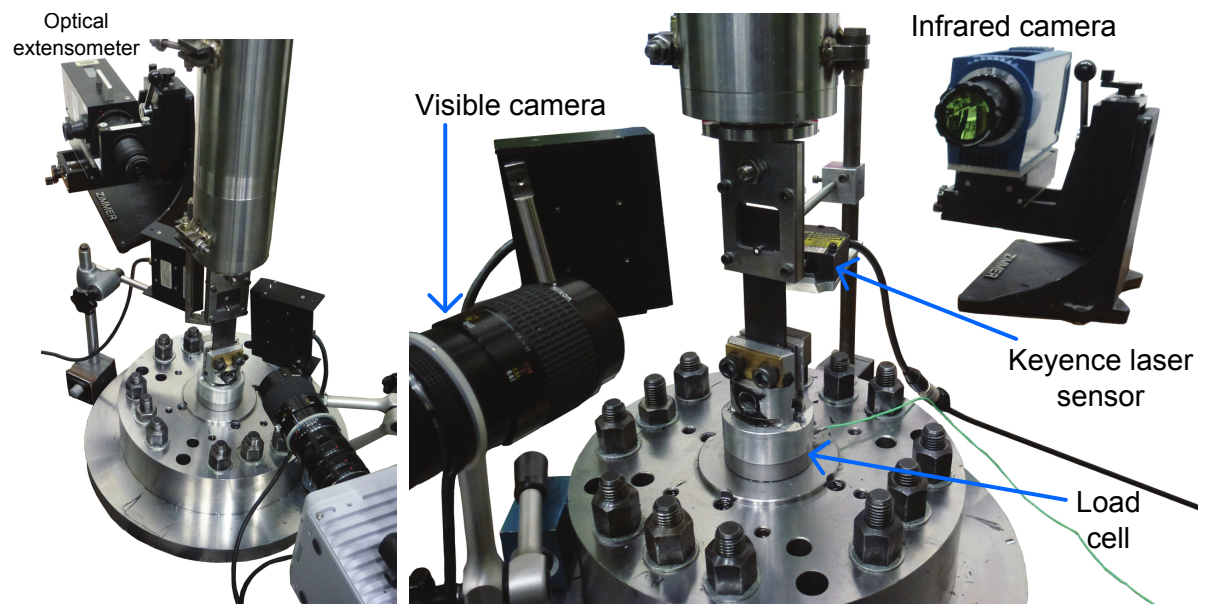

Figure 3: Global views of the experimental set-up with the different measurement systems

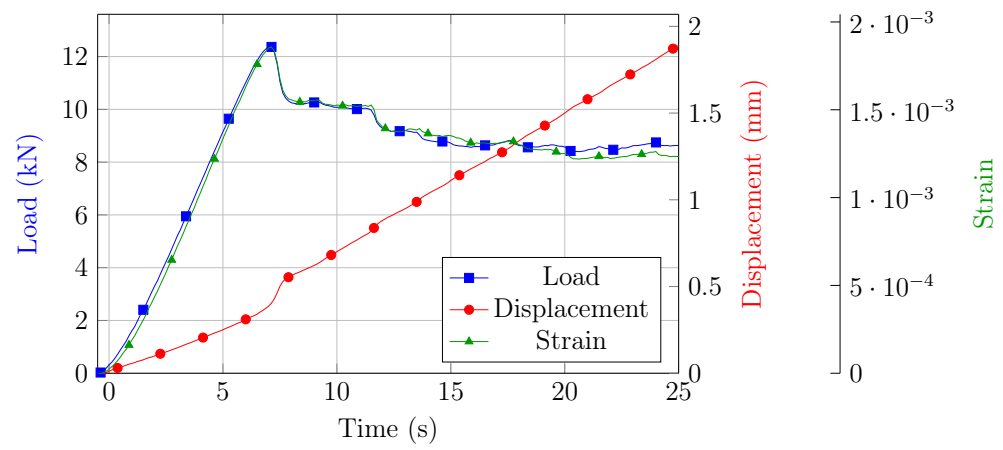

Figure 4: Evolution of the load, displacement and strain measured values during a $8.3 \cdot 10^{-5} \mathrm{~m} . \mathrm{s}^{-1}$ test 

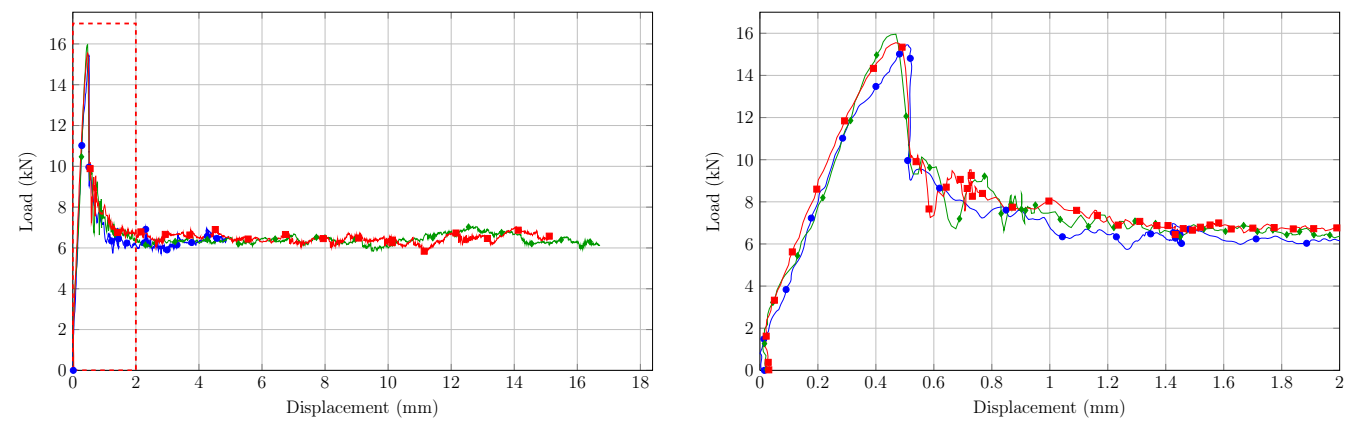

Figure 5: Evolution of the different measured values for the three tests performed at $1 \mathrm{~m} . \mathrm{s}^{-1}$

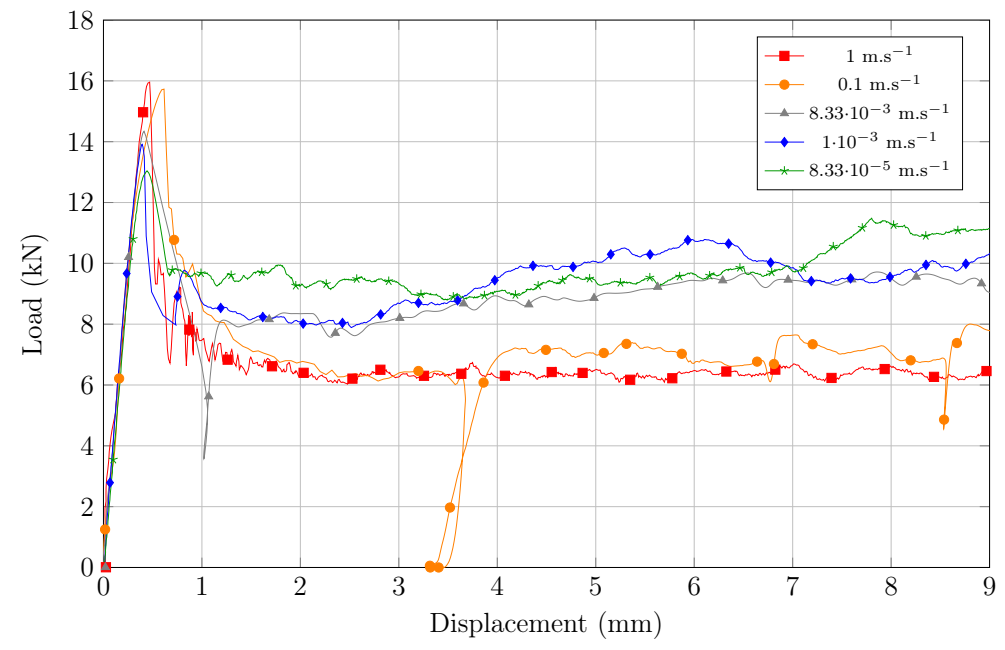

Figure 6: Evolution of the bearing response with respect to the loading rates 


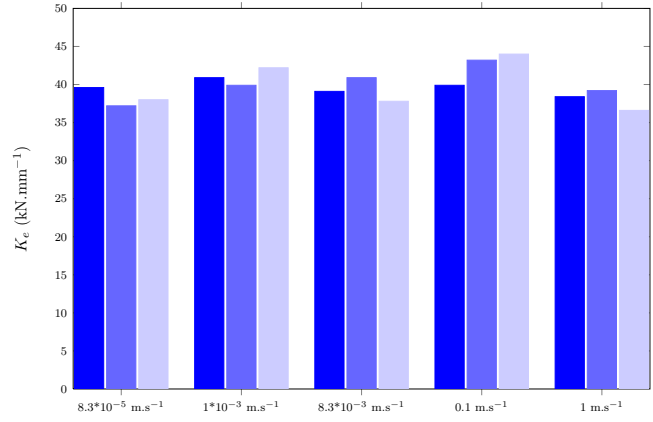

(a) $K_{e}$

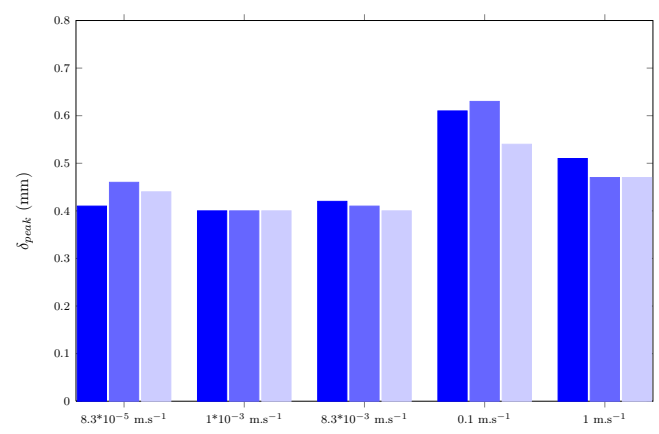

(c) $\delta_{\text {peak }}$

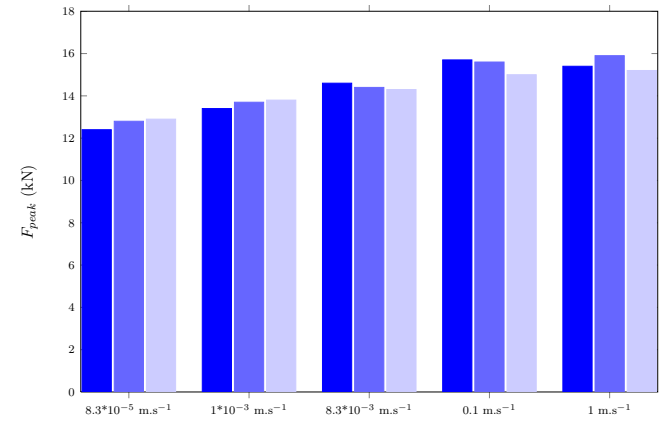

(b) $F_{\text {peak }}$

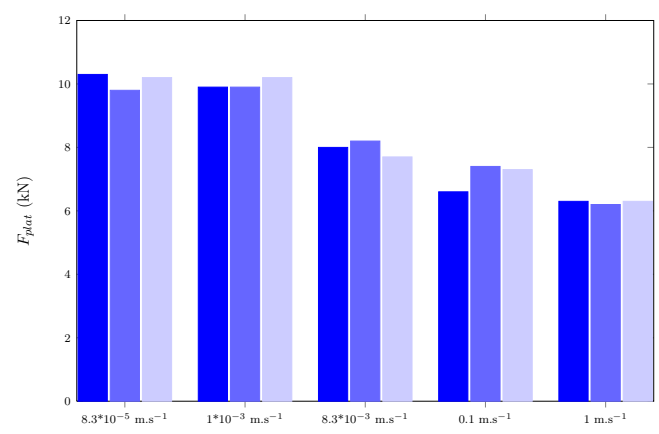

(d) $F_{\text {plat }}$

Figure 7: Test results evolution of the global bearing parameters with respect to the loading rate 


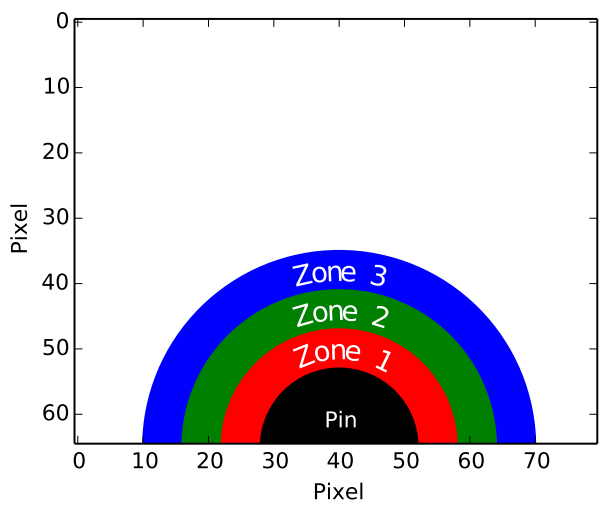

Figure 8: Description of the three processing zones for the IT and DIC analyse

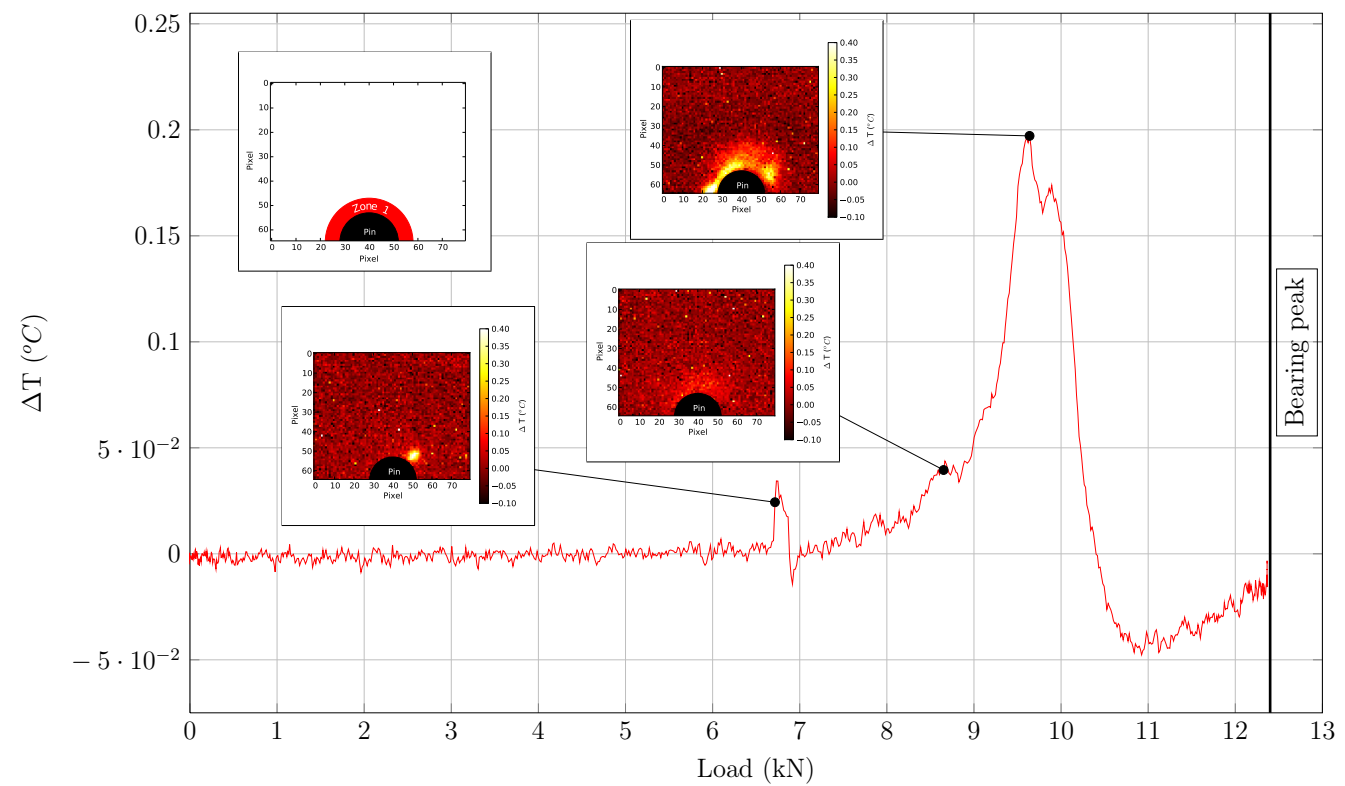

Figure 9: Evolution of the mean value of temperature change computed with the sliding windows for a test speed of $8.3 \cdot 10^{-5}$ m.s ${ }^{-1}$ in Zone 1 


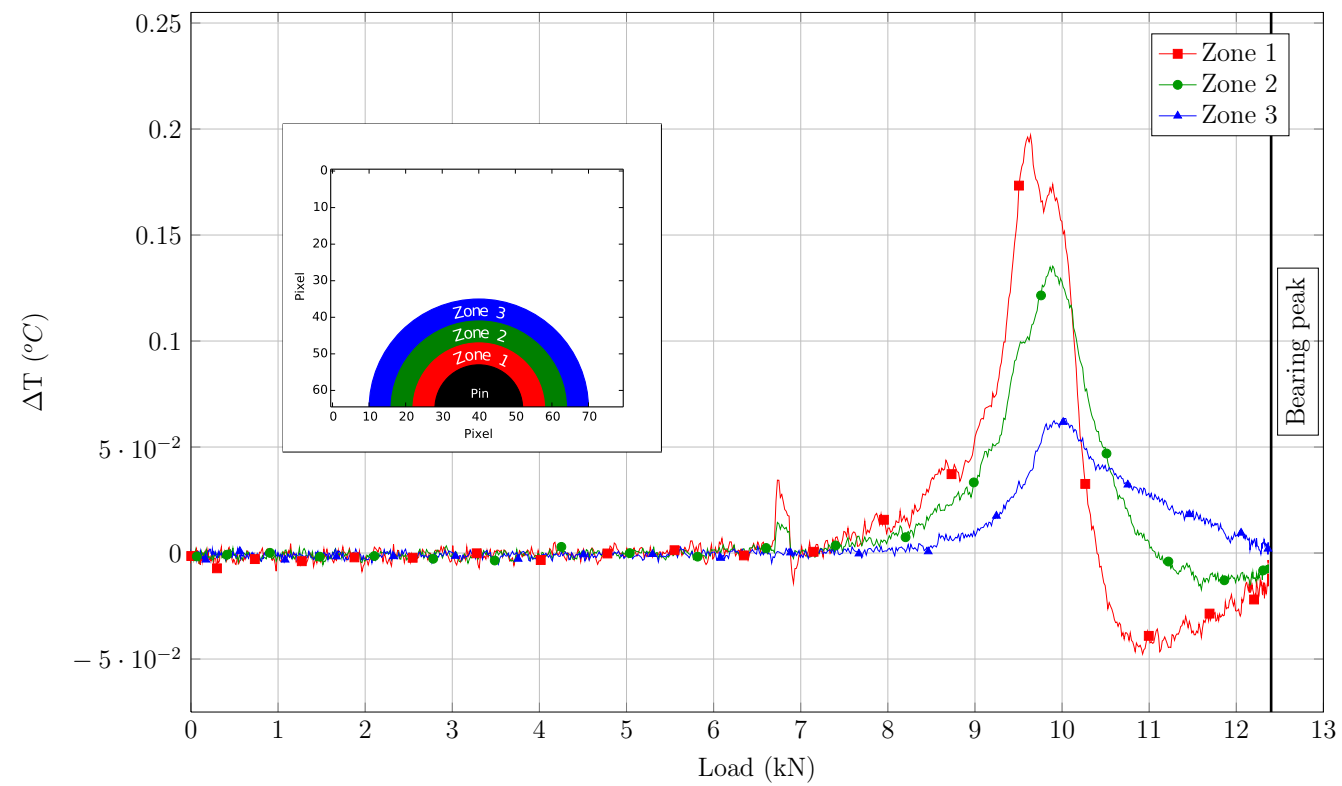

Figure 10: Evolution of the mean value of the temperature change computed with the sliding windows for a test speed of $8 \cdot 3 \cdot 10^{-5} \mathrm{~m} \cdot \mathrm{s}^{-1}$ in zones 1 to 3

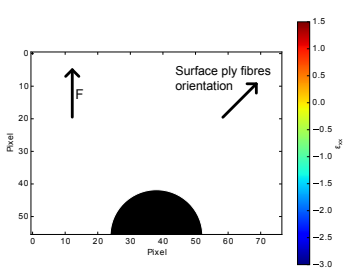

(a) $\varepsilon_{x x}$

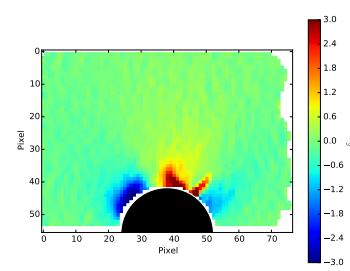

(b) $\varepsilon_{y y}$

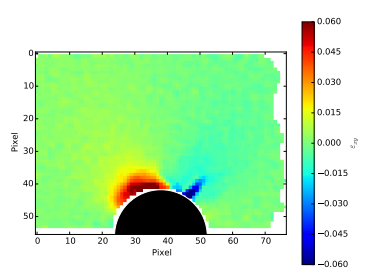

(c) $\varepsilon_{x y}$

Figure 11: Strain fields observed just before the bearing peak $F=12950 \mathrm{~N}$ for a test speed of $8.3 \cdot 10^{-5} \mathrm{~m} . \mathrm{s}^{-1}$ 


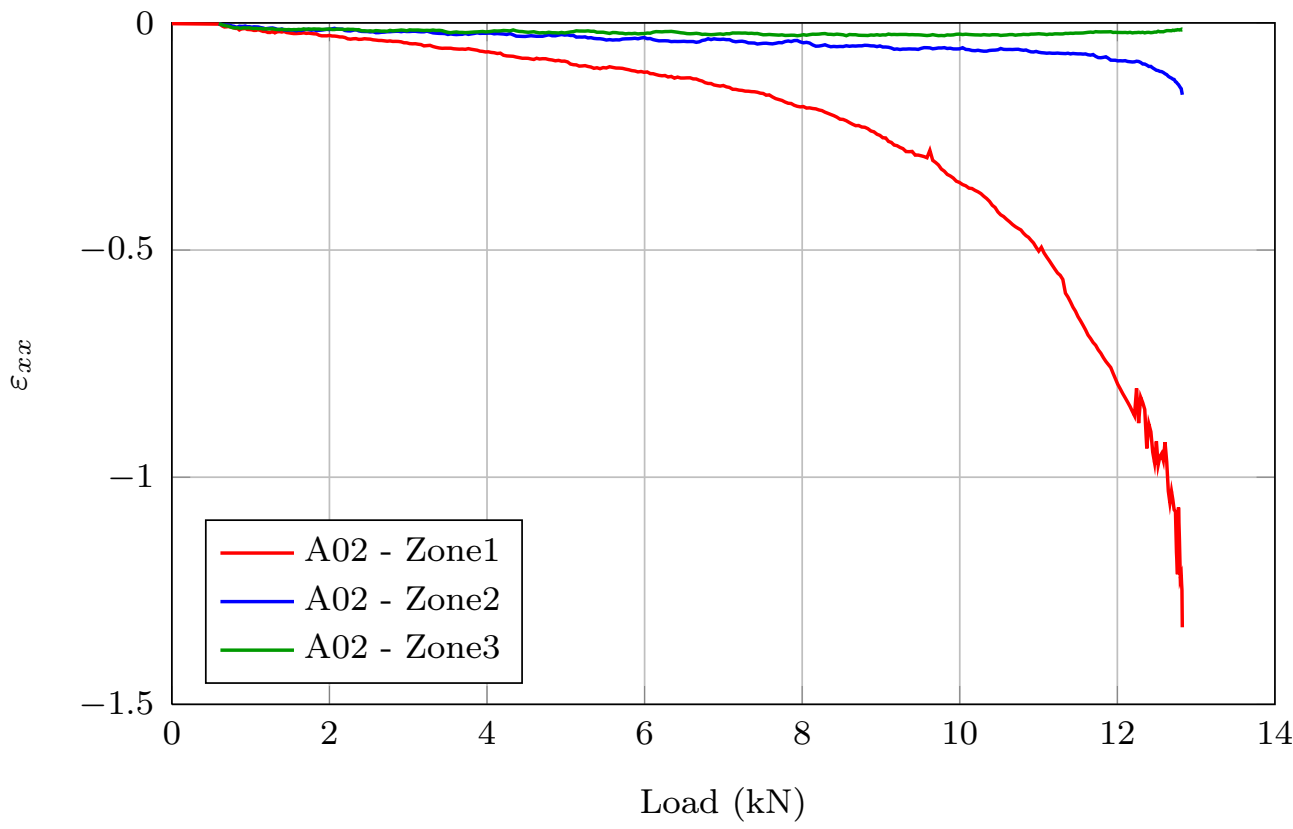

Figure 12: Evolution of the mean of the strain $\varepsilon_{x x}$ for a test speed of $8.3 \cdot 10^{-5}$ $\mathrm{m} . \mathrm{s}^{-1}$ in different zone close to the pin 


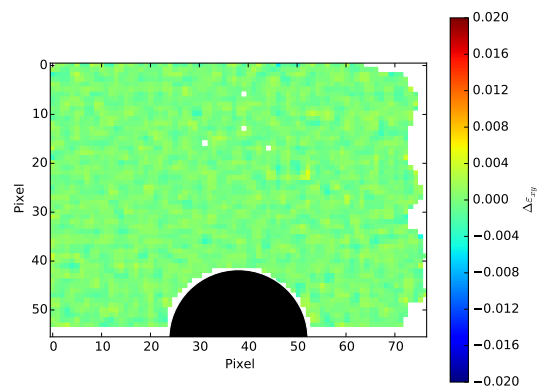

(a) before the matrix cracking

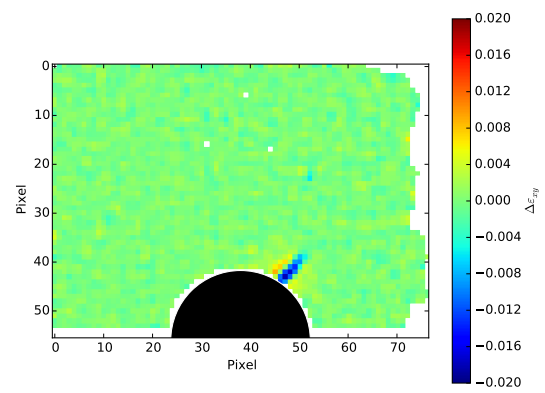

(b) after the matrix cracking

Figure 13: Map of the shear strain field variation $\Delta \varepsilon_{x y}$ plotted just before the matrix cracking in the surface ply on the left hand side $F=11750 \mathrm{~N}$ and just after on the right hand side $F=11778 \mathrm{~N}$ for a test speed of $8.3 \cdot 10^{-5}$ $\mathrm{m} \cdot \mathrm{s}^{-1}$ 


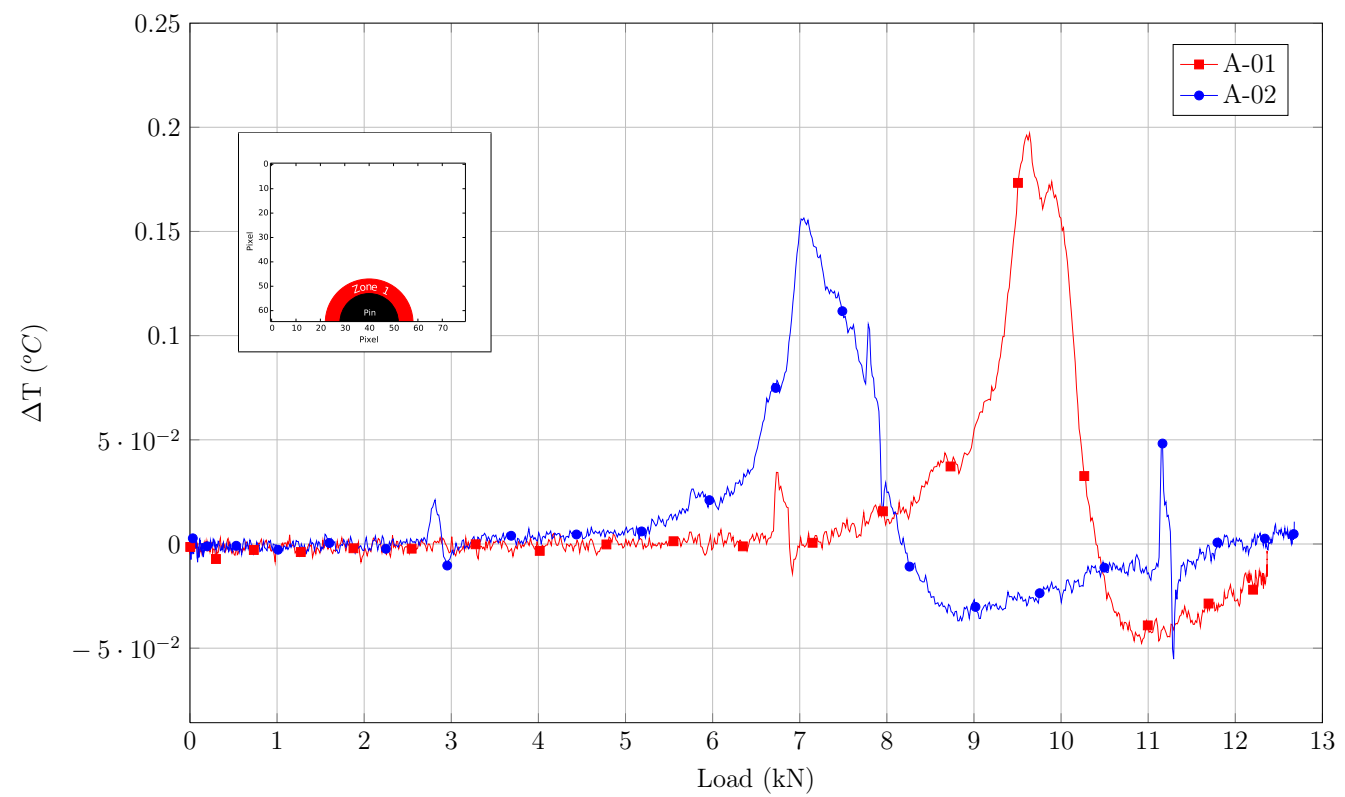

Figure 14: Comparison of the evolution of the temperature change mean value for two tests performed at $8 \cdot 3 \cdot 10^{-5} \mathrm{~m} . \mathrm{s}^{-1}$ in the first zone close to the pin 


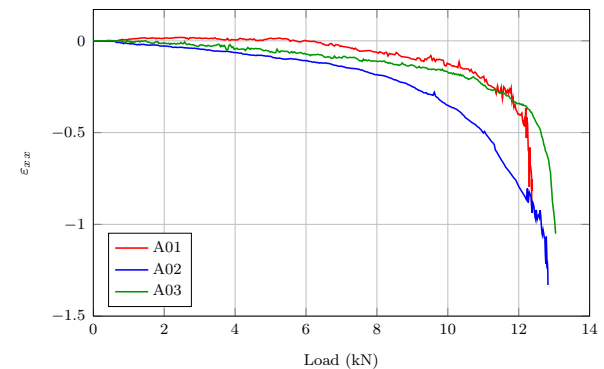

(a) $8.3 \cdot 10^{-5} \mathrm{~m} \cdot \mathrm{s}^{-1}$

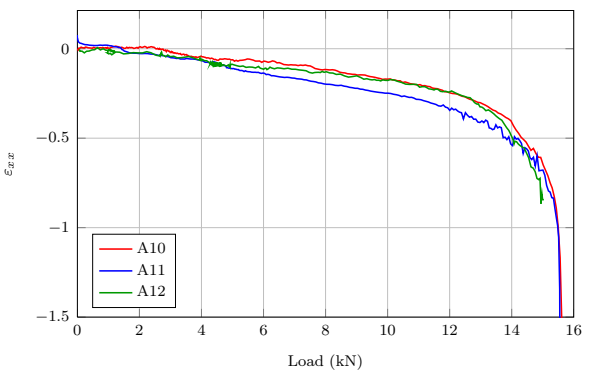

(b) $0.1 \mathrm{~m} \cdot \mathrm{s}^{-1}$

Figure 15: Evolution of the mean of the strain $\varepsilon_{x x}$ in zone1 for all tests performed for the loading rate of $8 \cdot 3 \cdot 10^{-5} \mathrm{~m} . \mathrm{s}^{-1}$ (left hand side) and for the loading rate of $0.1 \mathrm{~m} \cdot \mathrm{s}^{-1}$ (right hand side)

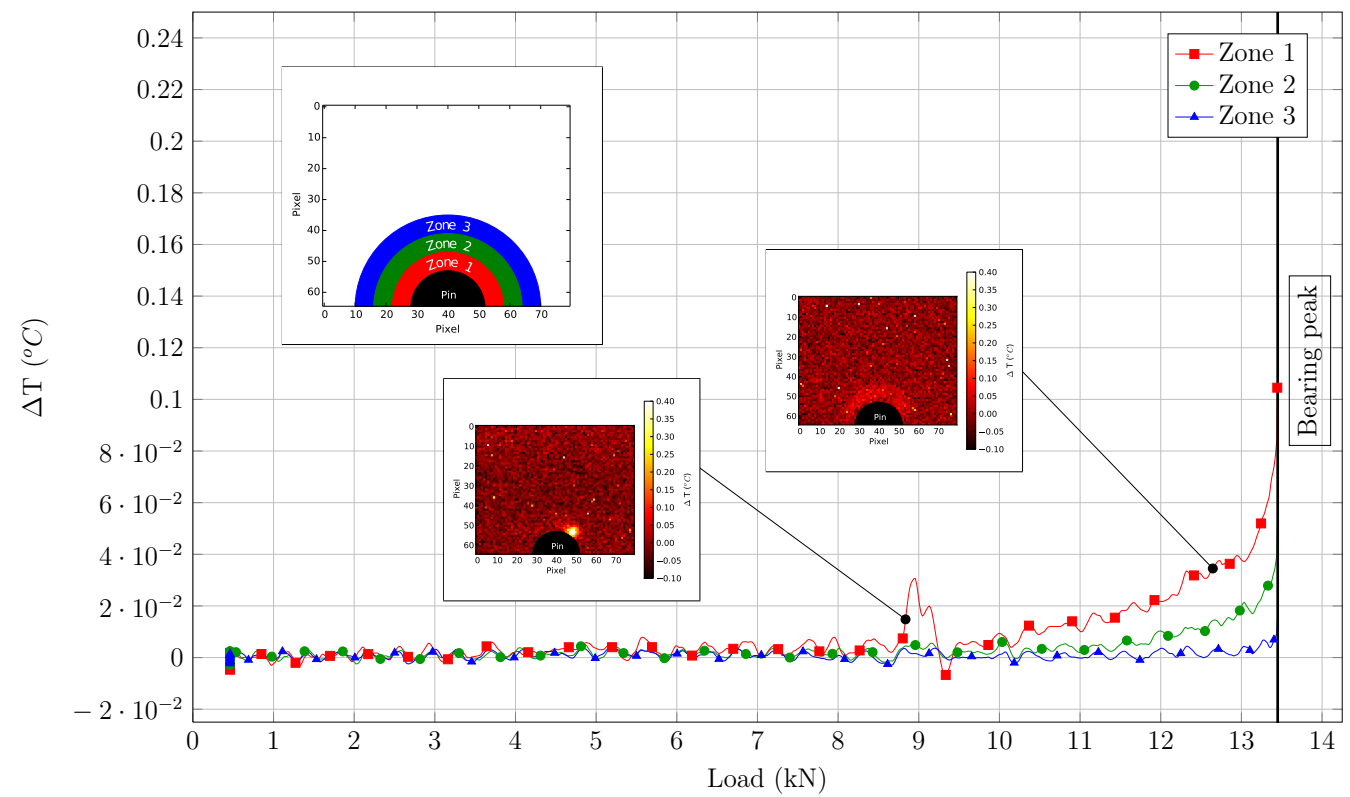

Figure 16: Evolution of $\Delta T$ mean value for a test speed of $1 \cdot 10^{-3} \mathrm{~m} . \mathrm{s}^{-1}$ in different zone close to the pin 


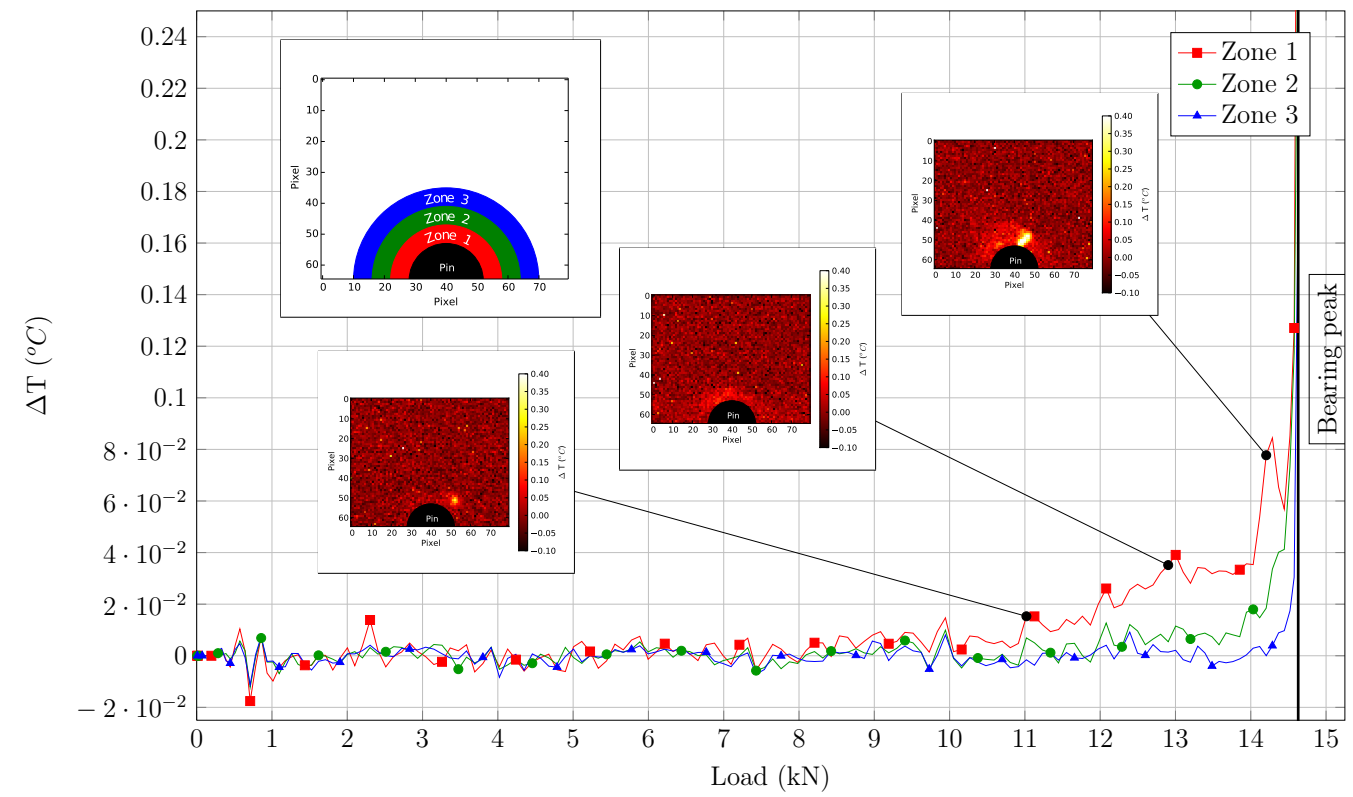

Figure 17: Evolution of $\Delta T$ mean value in the zone 1 (see Figure 8 ) for the three tests performed at $8.3 \cdot 10^{-3}$ m.s ${ }^{-1}$ 


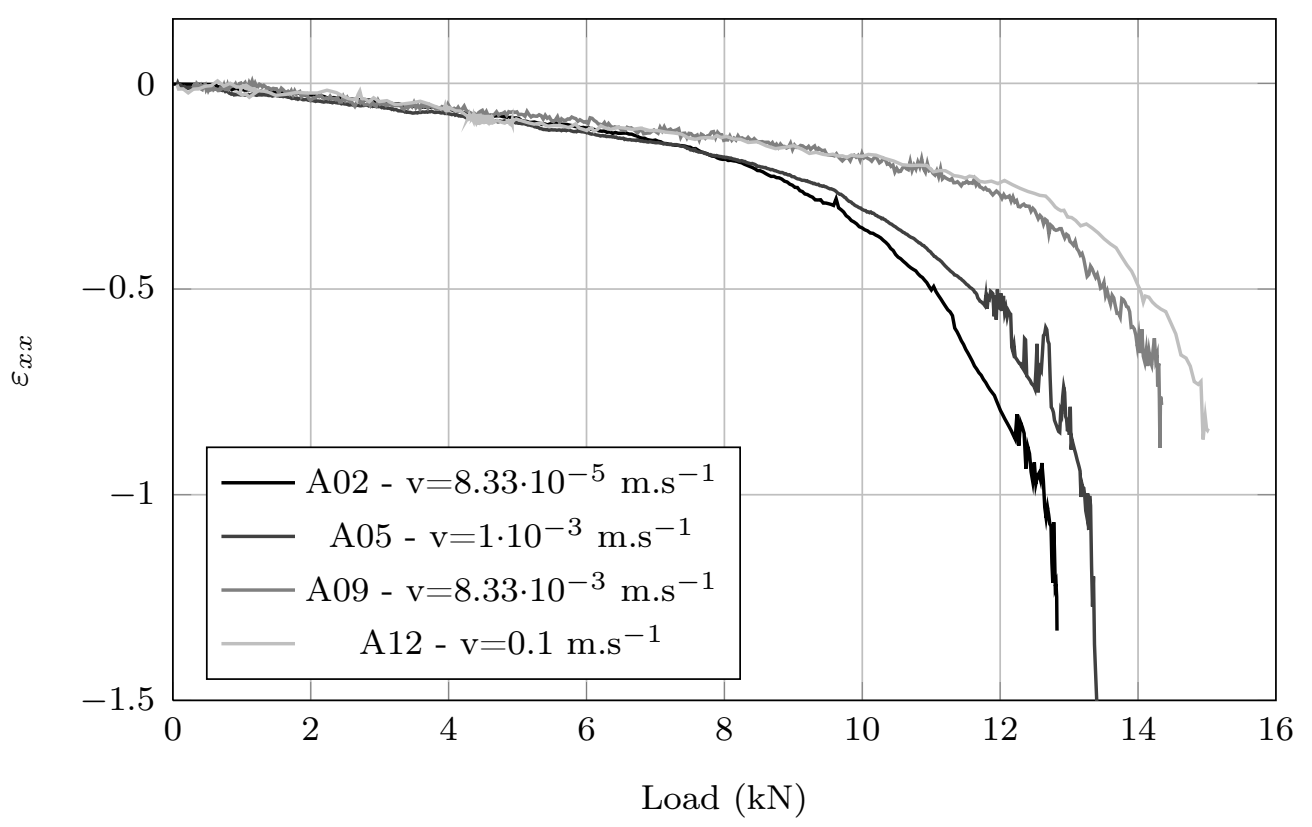

Figure 18: Evolution of the mean of the strain $\varepsilon_{x x}$ for all speed in zone1 